\title{
A Bifunctional MOF Catalyst containing Metal-Phosphine and Lewis Acidic Active Sites
}

\author{
Ram R. R. Prasad, ${ }^{[a]}$ Daniel M. Dawson, ${ }^{[a]}$ Paul A. Cox ${ }^{[b]}$ Sharon E. Ashbrook, ${ }^{[a]}$ Paul A. Wright ${ }^{*[a]}$ \\ and Matthew L. Clarke ${ }^{\star[a]}$
}

\begin{abstract}
Post-synthetic modification of the hafnium metal-organic framework MOF-808(Hf) to include triarylphosphine ligands is reported. Sulfonated phenylphosphines are incorporated without oxidation to give a 'MOF-ligand' that can complex late transition metals such as Ir and $\mathrm{Rh}$ to give a bifunctional catalyst containing both metal-phosphine complexes and the Lewis acidic framework hafnium metal sites. The metallated phosphine-bearing MOFs act as fully heterogeneous bifunctional catalysts for tandem reductive amination and hydroaminomethylation reactions.
\end{abstract}

\section{Introduction}

Metal-organic frameworks (MOFs) ${ }^{[1]}$ are now investigated intensively as catalysts. ${ }^{[2]}$ Some possess inherent Lewis acidity due to the presence of coordinatively unsaturated metal sites in their frameworks, ${ }^{[3]}$ while in others catalytically-active species can be introduced post synthesis. These may be transition metal atoms bound at sites pre-designed by linker choice, intact transition metal pre-catalysts, precious metal nanoparticles or even enzymes. ${ }^{[4-6]}$ In these cases, a catalyst known to be active under homogeneous conditions is immobilized in a well-defined, highly porous and tunable (but otherwise inert) crystalline environment. Attractive opportunities arise for the wider application of MOF catalysis where synergistic use can be made of active sites at framework metal cations and additional catalytic species incorporated by design into the MOF. A few initial papers have appeared that point towards a bright future for this approach ${ }^{[7]}$ However, none of these bifunctional catalysts feature arguably the mainstay of homogeneous catalysis, metalphosphine complex catalysts. It can be envisaged that new reactions with unusual selectivity, new tandem processes and reaction cascades will become possible using porous Lewis acidic MOFs that contain catalytically active metal-phosphine complexes. The diverse reactivity patterns and the industrial importance of catalysts of this type make the introduction of bifunctional MOFs containing metal-phosphine complexes of special significance.

[a] R. R. R. Prasad, Dr. D. M. Dawson, Prof. S. E. Ashbrook, Prof. P. A. Wright, Prof. M. L. Clarke

EaStCHEM School of Chemistry, University of St Andrews,

Purdie Building, North Haugh, St Andrews, KY16 9ST

United Kingdom

E-mail: paw2@st-andrews.ac.uk, mc28@st-andrews.ac.uk

[b] Dr. Paul A. Cox

School of Pharmacy and Biomedical Sciences,

University of Portsmouth, St Michael's Building

White Swan Road, Portsmouth, PO1 2DT

United Kingdom
The ubiquity of metal-phosphine catalysts stems from the relative ease with which a collection of catalysts with differing steric and electronic properties can be tested in a desired transformation. Typically, many different phosphorous ligands are tested, leading to the identification of a promising catalyst that is then further optimized for application. Relatively few synthetic routes to phosphine-functionalized MOFs have been developed so far. Pioneering works on MOFs containing phosphorous compounds report preparation of novel phosphinefunctionalised linkers and their incorporation into MOFs via coordination with a suitable metal. ${ }^{[5,8]}$ However, this route is inconsistent with the practically-important requirement to examine various ligand parameters by testing libraries of new ligands. Neither does it lend itself to the reliable preparation of a series of MOFs with coordinatively unsaturated metal cation sites and similar pore sizes, where the effect of varying a single parameter - the metal-phosphine active site - can be monitored. To establish bifunctional MOFs as versatile and tunable catalysts, we therefore had to address this challenge of introducing known phosphines into specific Lewis acidic MOFs. Here we show how post-synthetic modification can be used to make bifunctional MOFs based on MOF-808 (Figure 1$)^{[9]}$ that contain both Lewis acidic and metal-phosphine catalytic sites.

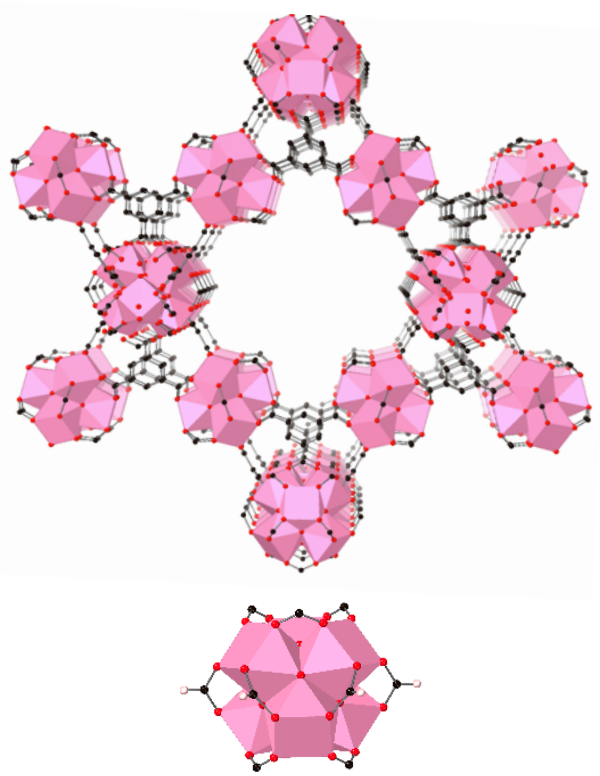

Figure 1. (Above) Polyhedral and ball-stick representation of the structure of MOF- $808^{[9]}$. Each $\mathrm{M}_{6} \mathrm{O}_{8} \quad(\mathrm{M}=\mathrm{Zr}$, Hf) cluster is coordinated to six benzenetricarboxylate (BTC) ligands and six formates $\left(\mathrm{HCO}_{2}\right)$. (Below) The 6connected $\mathrm{M}_{6}$ cluster of MOF-808. The carboxylate groups in axial and equatorial positions are from BTC and formate groups respectively. Hydrogen atoms of formate groups are omitted from the structure for clarity but shown in the cluster. 


\section{Results and Discussion}
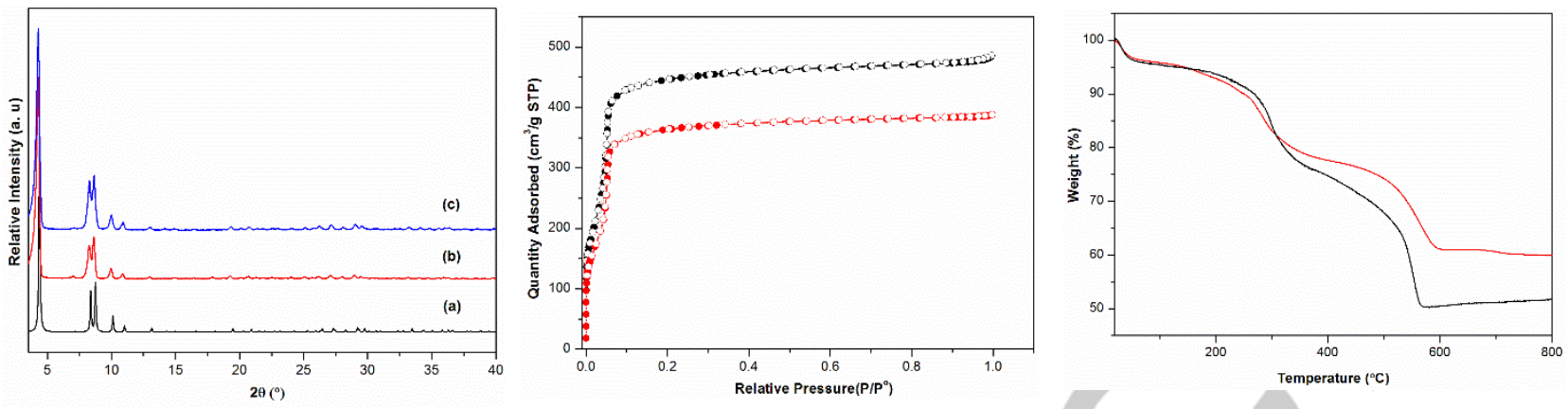

Figure 2. (Left) Powder X-ray diffraction patterns (PXRDs) of (b) activated MOF-808(Zr) and (c) activated MOF-808(Hf) compared with (a) the simulated pattern of MOF-808(Hf) ${ }^{[12 c]}$ (Middle) $\mathrm{N}_{2}$ adsorption isotherm of MOF-808( $\mathrm{Zr}$ ) (black) and MOF-808(Hf) (red) at $-196{ }^{\circ} \mathrm{C}$ after activation (heated under vacuum) at $150{ }^{\circ} \mathrm{C}$ for $16 \mathrm{~h}$. (Right) TGA of MOF-808(Zr) (black) and MOF-808(Hf) (red).

Our requirements for the platform MOF were that it should possess strong Lewis acidity and large pore size, and that it should be readily functionalised with the phosphine. After an initial screen through a series of reported early transition metalbased Lewis acidic MOFs for their activity in imine formation (Table 1), the large pore $(1.8 \mathrm{~nm})$ structure of MOF-808 $(\mathrm{Zr})^{[9]}$ (Figure 1), originally prepared as a zirconium 1,3,5-benzene tricarboxylate,

$\mathrm{Zr}_{6}\left(\mu_{3}-\mathrm{O}\right)_{4}\left(\mu_{3}-\mathrm{OH}\right)_{8}\left(\mathrm{HCO}_{2}\right)_{6}\left(\left(\mathrm{O}_{2} \mathrm{C}\right)_{3} \mathrm{C}_{6} \mathrm{H}_{3}\right)_{6 / 3}$ seemed ideal, in light of its high activity and the recent demonstration that formate groups on the secondary building units (SBUs) can be interchanged with other anions, such as carboxylates or sulfonates, via post-synthetic modification. ${ }^{[10,11]}$ We speculated that it might be possible to conduct this exchange using known sulfonated phosphine ligands, the strong $\mathrm{Zr}-\mathrm{O}$ bonds being expected to ensure that the cluster remains intact throughout the post-synthetic modification. Inspired by the higher Lewis acidity of PCN-777(Hf) compared with its $\mathrm{Zr}$ analogue (Table 1, Entries 7 and 8 ), the $\mathrm{Hf}$ version of MOF$808(\mathrm{Zr})$, MOF-808(Hf), was synthesised as micron-sized crystals by a method similar to that subsequently reported by Liu et al $^{[12]}$ (Figure 2). Nitrogen porosimetry at $-196{ }^{\circ} \mathrm{C}$ showed it had lower specific uptake (BET surface area of $1201 \mathrm{~m}^{2} \mathrm{~g}^{-1}$ ) than the $\mathrm{Zr}$ form $\left(1546 \mathrm{~m}^{2} \mathrm{~g}^{-1}\right)$ in line with its higher formula weight (Figure 2). The presence of formate groups in MOF-808(Hf) reported as being attached to the $\mathrm{Hf}_{6} \mathrm{O}_{8}$ clusters was indicated by thermogravimetric analysis/mass spectrometry, TGA-MS, where a mass loss at ca. $250{ }^{\circ} \mathrm{C}$ is accompanied by the evolution of $\mathrm{CO}_{2}(\mathrm{~m} / \mathrm{z}=44)$ (Figure S29). MOF-808(Hf) demonstrated the Lewis acidity required to promote imine synthesis, where it was among the most active large pore MOFs we have tested for this reaction, including $\mathrm{PCN}-777(\mathrm{Hf})$, which possesses the same $\mathrm{Hf}_{6} \mathrm{O}_{8}$ clusters, and it was certainly more active than its $\mathrm{Zr}$ analogue (Table 1, Entries 9 and 10)

Using the method of exchanging formate groups on the $\mathrm{M}_{6} \mathrm{O}_{8}$ clusters by sulfate groups using aqueous sulfuric acid by Jiang et al. ${ }^{[11]}$ for MOF-808(Zr), it was found that for MOF-808(Hf) the resulting solid showed no mass loss at $250^{\circ} \mathrm{C}$ in the TGA, supporting the assignment of this loss to thermal removal of carbon dioxide by formate decomposition (Figure S38). This formate-sulfate exchange is possible without the loss of crystallinity or porosity (Figures S39 and S40). Subsequently, similar reaction using $p$-toluenesulfonic acid (PTSA) was attempted to prove that aryl sulfonates could be included in the same way. MOF-808( $\mathrm{Hf})$ was soaked for $24 \mathrm{~h}$ in an aqueous solution of PTSA containing enough sulfonates to exchange one
Table 1. Evaluation of MOFs as Lewis acid catalysts for imine synthesis

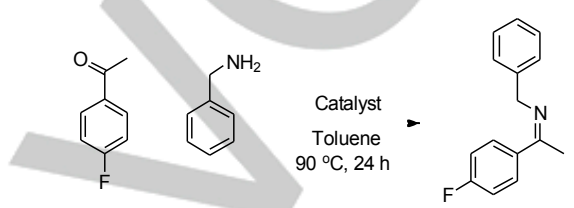

\begin{tabular}{|c|c|c|c|}
\hline Entry $^{[\mathrm{a}]}$ & Catalyst & \multicolumn{2}{|c|}{ Imine $(\%)^{[c]}$} \\
\hline 1 & None & - & $\sim 8$ \\
\hline 2 & $\mathrm{UiO}-66(\mathrm{Zr})$ & $\mathrm{Zr}_{6}\left(\mu_{3}-\mathrm{O}\right)_{4}\left(\mu_{3}-\mathrm{OH}\right)_{4}\left(\mathrm{O}_{2} \mathrm{C}-\right)_{12}$ & $\sim 7$ \\
\hline 3 & $\mathrm{Zr}-\mathrm{ABDC}$ & $\mathrm{Zr}_{6}\left(\mu_{3}-\mathrm{O}\right)_{4}\left(\mu_{3}-\mathrm{OH}\right)_{4}\left(\mathrm{O}_{2} \mathrm{C}-\right)_{12}$ & 10 \\
\hline 4 & $\mathrm{PCN}-222(\mathrm{Zr})$ & $\mathrm{Zr}_{6}\left(\mu_{3}-\mathrm{OH}\right)_{8}(\mathrm{OH})_{8}\left(\mathrm{O}_{2} \mathrm{C}-\right)_{8}$ & 18 \\
\hline 5 & $\mathrm{PCN}-224(\mathrm{Zr})$ & $\mathrm{Zr}_{6}\left(\mu_{3}-\mathrm{O}\right)_{4}\left(\mu_{3}-\mathrm{OH}\right)_{4}\left(\mathrm{OH}_{6}\right)\left(\mathrm{H}_{2} \mathrm{O}\right)_{6}\left(\mathrm{O}_{2} \mathrm{C}-\right)_{6}$ & 28 \\
\hline 6 & $\mathrm{NU}-1200(\mathrm{Zr})$ & $\mathrm{Zr}_{6}\left(\mu_{3}-\mathrm{O}\right)_{4}\left(\mu_{3}-\mathrm{OH}\right)_{8}\left(\mathrm{H}_{2} \mathrm{O}\right)_{8}\left(\mathrm{O}_{2} \mathrm{C}-\right)_{8}$ & 51 \\
\hline 7 & $\mathrm{PCN}-777(\mathrm{Zr})$ & $\mathrm{Zr}_{6}\left(\mu_{3}-\mathrm{O}\right)_{4}(\mathrm{OH})_{10}\left(\mathrm{H}_{2} \mathrm{O}\right)_{6}\left(\mathrm{O}_{2} \mathrm{C}-\right)_{6}$ & $\sim 5$ \\
\hline 8 & $\mathrm{PCN}-777(\mathrm{Hf})$ & $\mathrm{Hf}_{6}\left(\mu_{3}-\mathrm{O}\right)_{4}(\mathrm{OH})_{10}\left(\mathrm{H}_{2} \mathrm{O}\right)_{6}\left(\mathrm{O}_{2} \mathrm{C}-\right)_{6}$ & 32 \\
\hline 9 & MOF-808(Zr) & $\mathrm{Zr}_{6}\left(\mu_{3}-\mathrm{O}\right)_{4}\left(\mu_{3}-\mathrm{OH}\right)_{8}\left(\mathrm{HCO}_{2}\right)_{6}\left(\mathrm{O}_{2} \mathrm{C}-\right)_{6}$ & 65 \\
\hline 10 & MOF-808(Hf) & $\mathrm{Hf}_{6}\left(\mu_{3}-\mathrm{O}\right)_{4}\left(\mu_{3}-\mathrm{OH}\right)_{8}\left(\mathrm{HCO}_{2}\right)_{6}\left(\mathrm{O}_{2} \mathrm{C}-\right)_{6}$ & 85 \\
\hline 11 & $\mathrm{ScBTB}$ & $\mathrm{Sc}_{3} \mathrm{O}\left(\mathrm{HCO}_{2}\right)\left(\mathrm{O}_{2} \mathrm{C}-\right)_{6}$ & 70 \\
\hline 12 & MIL-100(Sc) & $\mathrm{Sc}_{3} \mathrm{O}\left(\mathrm{OH}, \mathrm{OH}_{2}\right)_{3}\left(\mathrm{O}_{2} \mathrm{C}-\right)_{6}$ & 80 \\
\hline
\end{tabular}

[a] Reaction conditions: $1 \mathrm{mmol}$ ketone, $1.3 \mathrm{mmol}$ benzyl amine and $1.5 \mathrm{~mol} \%$ catalyst in $5 \mathrm{~mL}$ toluene at $90{ }^{\circ} \mathrm{C}$ for $24 \mathrm{~h}$. The mol\% is calculated according to the molecular weight based on a formula unit containing one metal-oxygen cluster $\left(\mathrm{M}_{6} \mathrm{O}_{8}\right.$ or $\left.\mathrm{M}_{3} \mathrm{O}\right) \cdot{ }^{[\mathrm{b}]}\left(\mathrm{O}_{2} \mathrm{C}-\right)$ refers to carboxylate groups from the linkers or modulators used in the synthesis of MOFs. For linker structure, see ESI section 1.

${ }^{[c]}$ Conversions were determined by ${ }^{19} \mathrm{~F}$ NMR.

half of the formates calculated to be present in the MOF according to the reported chemical formula. ${ }^{[9]}$ The water was replaced with acetone and the solid was kept in this solvent for $24 \mathrm{~h}$ before activation under vacuum. The crystallinity of the product MOF-808(Hf)-PTSA, obtained in this way was confirmed by PXRD and $\mathrm{N}_{2}$ porosimetry showed the expected reduction in porosity due to incorporation of PTSA (Figures $3 A$ \& 3B). Furthermore, TGA of MOF-808(Hf)-PTSA showed the mass loss corresponding to the formate groups has been considerably reduced with respect to the parent MOF-808(Hf) by the tethering of PTSA, indicating successful post-synthetic modification (Figure $3 \mathrm{C}) .{ }^{13} \mathrm{C}$ CP MAS NMR of MOF-808(Hf)-PTSA after the activation showed peaks characteristic of PTSA along with those for linker BTC (Figure 3D). MOF-808(Hf)-PTSA retained its crystallinity even after two weeks when kept under ambient conditions as shown by PXRD (Figure S41). 

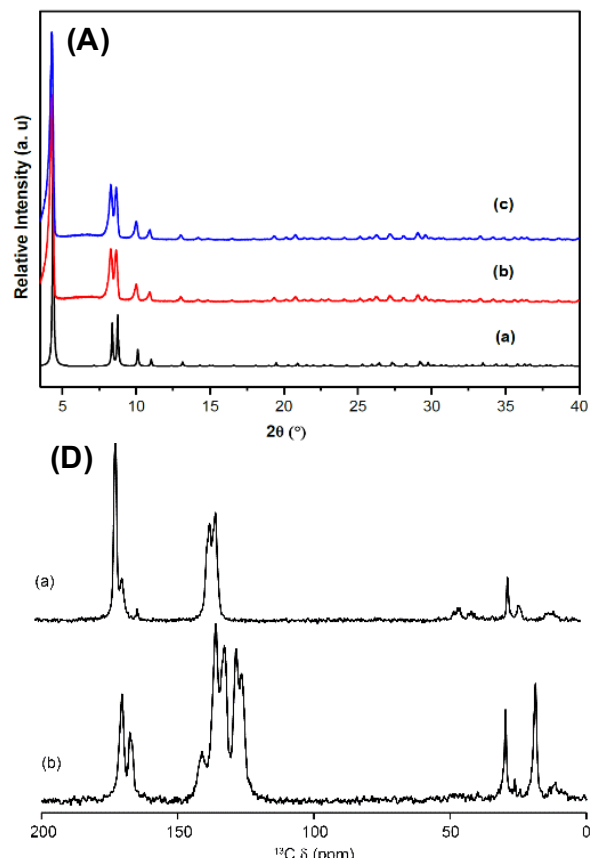
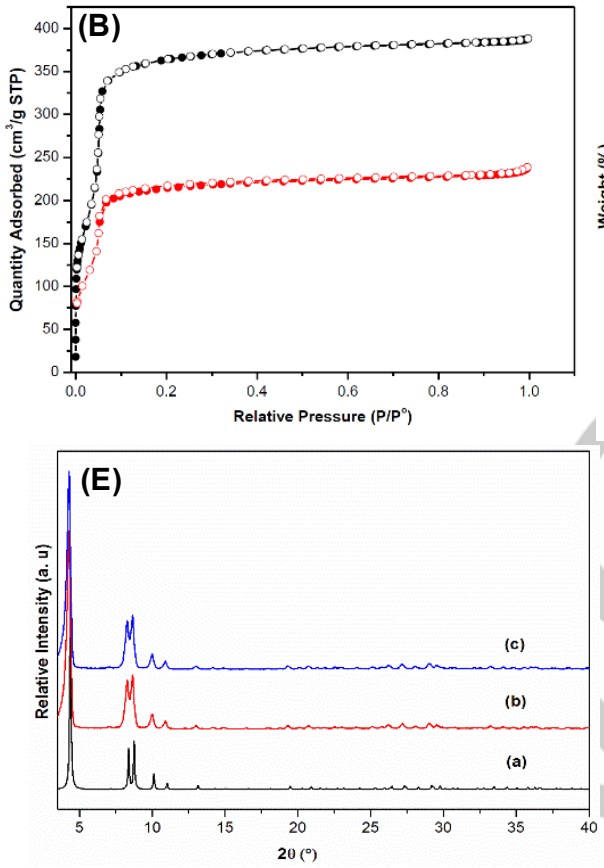

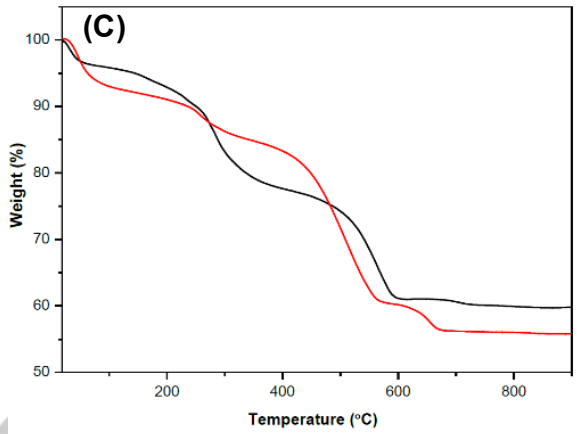

(F)

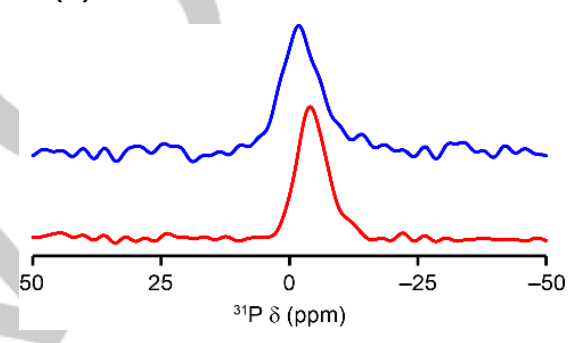

Figure 3. (A) PXRD pattern of (b) as-synthesised MOF-808(Hf)-PTSA and (c) activated MOF-808(Hf)-PTSA compared with (a) the simulated pattern of MOF$808(\mathrm{Hf})^{[12 c]}$, (B) $\mathrm{N}_{2}$ adsorption isotherm of MOF-808(Hf) (black) and MOF-808(Hf)-PTSA (red) at $-196{ }^{\circ} \mathrm{C}$ after activation at $150{ }^{\circ} \mathrm{C}$ for $16 \mathrm{~h}$, (C) TGA of MOF808(Hf) (black) with TGA of MOF-808(Hf)-PTSA (red), (D) ${ }^{13} \mathrm{C}$ CP MAS NMR spectra of (a) MOF-808(Hf) with (b) MOF-808(Hf)-PTSA (PTSA peaks marked with asterisk), (E) PXRD pattern of (b) as-synthesised SuIP1-MOF-808(Hf) and (c) SulP2-MOF-808(Hf) with the (a) simulated pattern of MOF-808(Hf) ${ }^{[12 c]}$ and

(F) ${ }^{31}$ P MAS NMR of SulP1-MOF-808(Hf) (red) and SulP2-MOF-808(Hf) (blue)

MOFs containing sulfonated phenylphosphines were subsequently prepared by this ligand exchange protocol. To provide sufficient accessible pore volume for the free movement of catalytic substrates and to access the active sites distributed throughout the framework, we thought it ideal to incorporate approximately one phosphine moiety per cage of MOF-808(Hf). The MOF and either the sodium salt of 3(diphenylphosphino)benzene sulfonic acid (SulP1 for anion) or the dipotassium salt of bis( $p$-sulfonatophenyl) phenylphosphine dihydrate (SulP2) were kept in degassed water for $24 \mathrm{~h}$ with occasional stirring and the water was replaced for degassed acetone and kept for $24 \mathrm{~h}$ prior to activation. Solvent exchange with acetone removes water from the MOF pores, thereby eliminating the capillary forces of water than can result in pore wall collapse and degradation of MOF structure upon activation. This gave SulP1-MOF-808(Hf) and SulP2-MOF-808(Hf) respectively (Scheme 1).

NMR of concentrated reaction solution indicated negligible amounts of phosphine were left in solution after the modification, so that the solids had empirical formulae of $\mathrm{Hf}_{6} \mathrm{O}_{4}(\mathrm{OH})_{4}(\mathrm{BTC})_{2}\left(\mathrm{HCO}_{2}\right)_{5.75}\left(\mathrm{SO}_{3}-\mathrm{PPh}_{3} \mathrm{R}\right)_{0.25}\left(\mathrm{R}=\mathrm{H}, \mathrm{SO}_{3}\right)$. EDX (Figure S44) and ICP analysis gave a $\mathrm{P} / \mathrm{Hf}$ value of 0.04 consistent with one phosphine per cage on average. PXRD (Figure 3E) of SulP1/SulP2-MOF-808(Hf) showed high crystallinity and ${ }^{31} \mathrm{P}$ MAS NMR spectroscopic analysis of both (Figure $3 \mathrm{~F}$ ) showed a peak at ca. -4 ppm characteristic of free phosphines. This simple procedure directly delivers phosphine introduction to MOF via post-synthetic modification and without the formation of any phosphine oxide species. A model structure (Figure 4) optimised using periodic density functional theory (DFT) code CASTEP ${ }^{[13]}$ using the generalised gradient approximation with Perdew-Burke-Ernzerhof (PBE) exchange correlation functional indicates that ligand can be included in the cages and space is still available for the substrates to access and products to leave the pores.

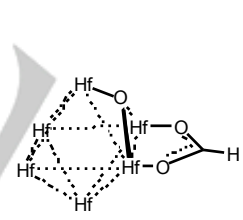<smiles>COc1cccc([PH](c2ccccc2)(c2ccccc2)c2cccc(OC)c2)c1</smiles>

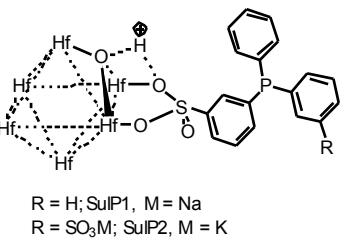

Scheme 1. Post-synthetic exchange of sulfonated phosphines for formate

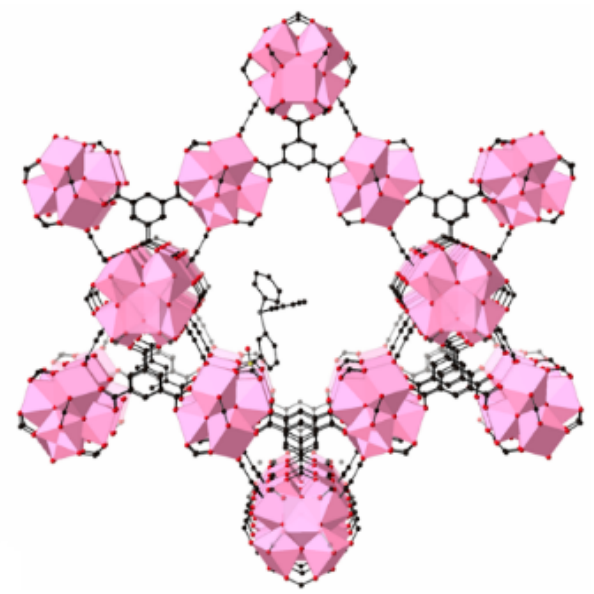

Figure 4. The DFT optimized model structure of SulP1-MOF-808(Hf), in which a formate group has been replaced by SuIP1. 
To establish that this phosphine-modified MOF can act as a platform for a range of bifunctional catalysts, we selected the direct reductive amination of ketones as a test reaction. This important reaction requires both Lewis acidity and hydrogenation catalysis. ${ }^{[14]}$ Most studies in this area have focused on homogeneous catalysts because of the requisite functional group tolerance in pharmaceutical synthesis, along with ongoing development of enantioselective reactions. In addition, hydrogenation is one of the most important applications of metal-phosphine catalysts.

To mimic the protocol by which many homogeneous catalytic processes are conducted, the MOF-phosphine was mixed with an appropriate metal precursor, $[\operatorname{IrCl}(\mathrm{COD})]_{2}$ or $\left[\mathrm{Rh}(\mathrm{acac})(\mathrm{CO})_{2}\right]$, with a metal:P ratio of $1: 1$ and then tested directly afterwards in the catalytic tandem reaction. The inclusion of the Ir precursor in the MOF-phosphine is visually apparent with the solution color associated with the homogeneous metal precursors disappearing after the reaction with the MOF and the MOF becoming coloured (Figure S47). A similar change was observed with the Rh complex. EDX reveals that the $\mathrm{Ir}$ is incorporated in the MOF (Figure S48). The pre-catalysts can be characterised by ${ }^{31} \mathrm{P}$ MAS NMR and show the expected downfield coordination shift to $25 \mathrm{ppm}$ relative to $-4 \mathrm{ppm}$ for the free phosphine (relative to $+40 \mathrm{ppm}$ for oxidised phosphine) in the ${ }^{31} \mathrm{P}$ MAS NMR spectrum for Ir (Figure 5) and similar shifts was observed for Rh coordination (Figure S49). If the precatalyst is removed at this point, PXRD reveals it is crystalline while its specific porosity is lowered by around $25 \%$ compared to the parent due to increase in the mass and occupation of pore space from ligand addition (Figures S50 and S51).

(a)

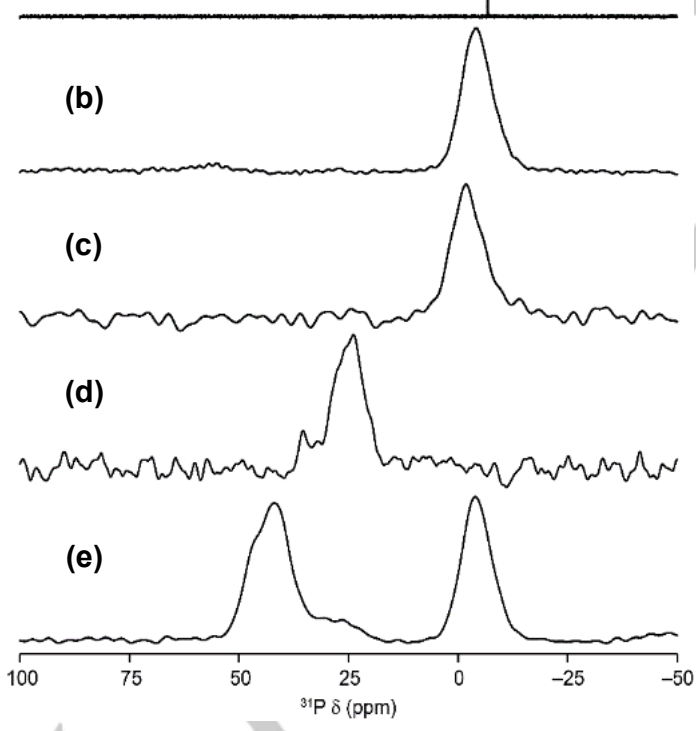

Figure 5. (a) ${ }^{31} \mathrm{P}$ solution state NMR of SulP1, ${ }^{31} \mathrm{P}$ MAS NMRs of (b) SulP1-MOF-808(Hf), (c) SulP2-MOF-808(Hf), (d) SulP1-MOF-808(Hf)-Ir and (e) SulP1-MOF-808(Hf) prepared in non de-oxygenated solvents that gave both free and oxidised phosphines.
Table 2. Optimisation of Reductive Amination ${ }^{[a]}$

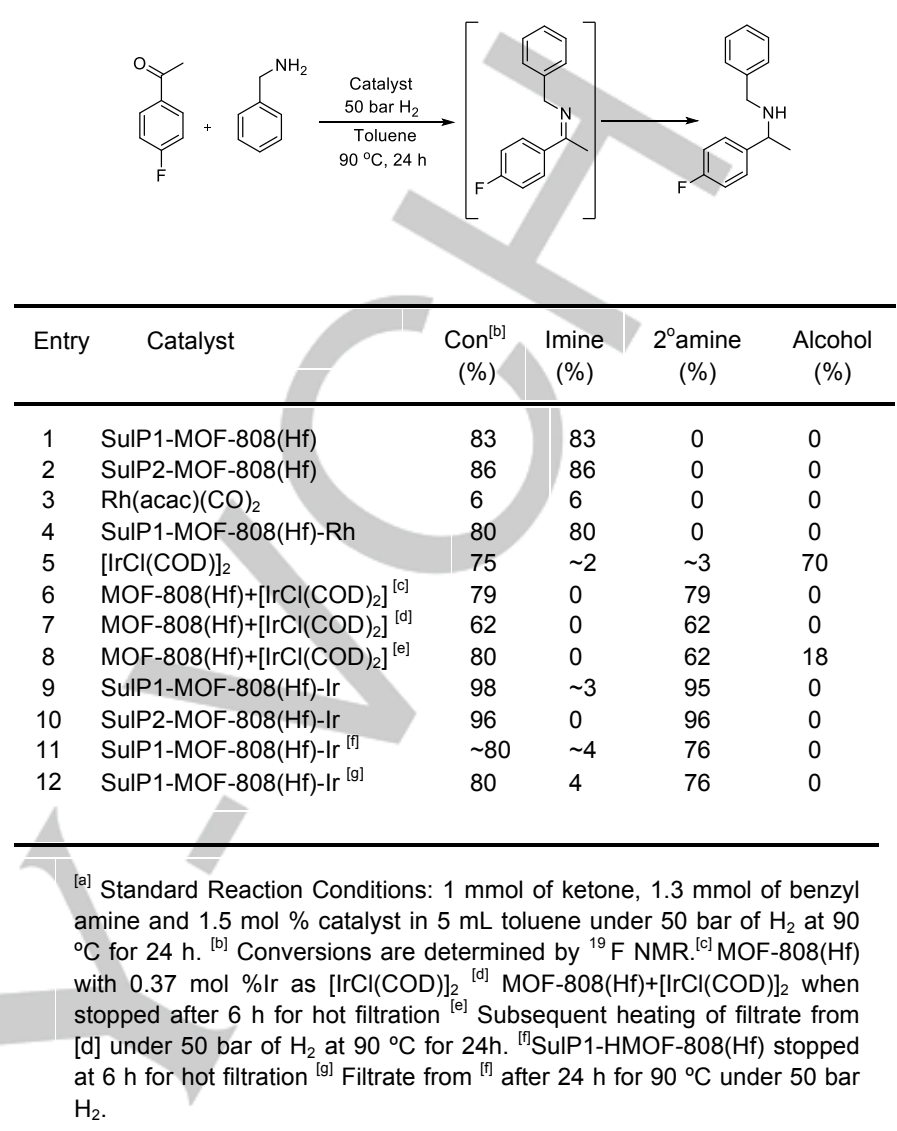

A series of reductive aminations of 4'-fluoroacetophenone were performed using different catalysts, the results of which are given in Table 2. As expected, if MOF-808(Hf) (Table 1, Entry 10 ) or SulP1/SulP2-MOF-808(Hf) is used alone, the only product detected is imine (Table 2, Entry 1,2). If the MOF ligand, SulP1MOF-808(Hf) is combined with $\left[\mathrm{Rh}(\mathrm{acac})(\mathrm{CO})_{2}\right]$, only imine formation takes place with no hydrogenation and use of $\left[\mathrm{Rh}(\mathrm{acac})(\mathrm{CO})_{2}\right]$ itself has no effect above background levels of imine formation (Table 2, Entry 3,4).

If $[\mathrm{IrCl}(\mathrm{COD})]_{2}$ is added to a solution of ketone, amine and the reaction performed at 50 bar, a black suspension of Iridium nanoparticles forms, and negligible imine formation takes place (Table 2, Entry 5). Instead, the major product is from the partial reduction of the ketone starting material to 2-(4fluorophenyl)ethanol. MOF-808(Hf) combined with $[\mathrm{IrCl}(\mathrm{COD})]_{2}$ does gives secondary amine as the major product (Table 2, Entry 6), but hot filtration and subsequent re-exposure of the filtrate to the reaction conditions gives 2-(4-fluorophenyl)ethanol, indicating the presence of leached iridium (Table 2, Entry 8). By contrast, both SulP1- and SulP2-MOF-808(Hf) with [IrCl(COD) $]_{2}$ showed high conversions and high selectivity towards secondary amine (Table 2, Entries 9,10), and demonstrate no observable leaching upon hot filtration, as measured by lack of filtrate activity for hydrogenation (Table 2, Entry 12, Figure S52). Thus, it is possible to form a permanently immobilised Ir metal catalyst if a phosphine is first tethered to the MOF. Furthermore, the Irphosphine catalysts are more active for reductive amination than those without phosphine. While it is well known that various 
combination of homogeneous catalysts can promote this reaction, ${ }^{[15]}$ this system has the advantage of an easy to remove catalyst. In fact, attempting to do this reaction homogeneously by replacing the MOF phosphine with $[\mathrm{IrCl}(\mathrm{COD})]_{2}$ and $\mathrm{PPh}_{3}$, or even mixture of $[\mathrm{IrCl}(\mathrm{COD})]_{2}, \mathrm{PPh}_{3}$ and $\mathrm{HfCl}_{4}$ delivers mainly the alcohol side product.(See Table S1 ESI). SuIP1-MOF-808(Hf) showed excellent conversion and selectivity towards secondary amine even after 5 catalytic cycles (Figure 6). No nanoparticle deposition was observed by transmission electron microscopic analysis on the MOF after catalysis (Figure S54). PXRD of SulP1-MOF-808(Hf)-Ir after catalysis shows the MOF retains its crystallinity under catalytic conditions (Figures S55 and 56). The $\mathrm{N}_{2}$ adsorption of a sample retrieved after catalytic testing shows the same type of isotherm as SulP1-MOF-808(Hf)-Ir before catalysis, although the uptake has been reduced by ca. one third due to a combination of structural loss during the catalysis, handling in air and subsequent activation and possible occupation of pore volume by adsorbed species.

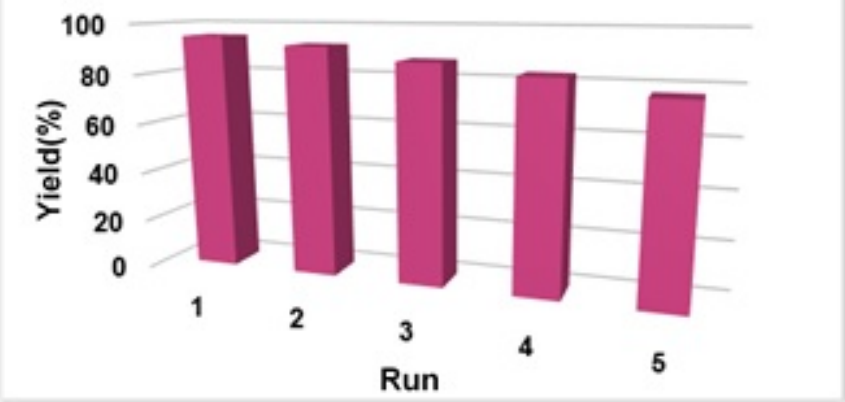

Figure 6. Plots of yields(\%) of N-benzyl-1-(4-fluorophenyl)ethan-1-amine at different runs in the recycle experiments of SulP1-MOF-808(Hf)-Ir for reductive amination of 4'-fluoroacetophenone with benzylamine.

SulP2-MOF-808(Hf)-Ir showed productivity towards $2^{\circ}$ amine similar to that of SulP1-MOF-808(Hf)-Ir, but the lower cost of the phosphine precursor made SulP1-MOF-808(Hf)-Ir our preferred catalyst for further expansion of the scope to a range of other acetophenone derivatives and primary amines (Table S1 and Scheme 2). High conversions and selectivities were observed. There is no hydrogenolysis of the benzyl group or, in $\mathbf{1 d}$, of the $\mathrm{C}-\mathrm{Br}$, which would be expected using typical heterogeneous hydrogenation catalysts. ${ }^{[16]}$

While the SulP1-MOF-808(Hf)-Ir gave good results in reductive amination of ketones, it is well known that reduction of aldimines is significantly easier than that of ketimines and we found that SulP1-MOF-808(Hf)-Rh was able to reductively aminate benzaldehyde (Scheme 3 ). With this precedent, we aimed to establish the versatile nature of SulP1-MOF-808(Hf) as an insoluble "porous phosphine ligand" with Lewis acidity, whose catalytic properties can be modified by the choice of metal precursor added. Therefore, we studied the hydroaminomethylation of alkenes to see if a bifunctional Rh MOF could promote such a sequential reaction. This atomeconomic domino reaction, which starts with hydroformylation of alkenes and is followed by reductive amination, is an important and efficient synthesis of amines. ${ }^{[17]}$ In our chosen exemplar reaction between cyclopentene and aniline (Scheme 4) with SulP1-MOF-808(Hf)-Rh (using $\mathrm{Rh}$ (acac) $(\mathrm{CO})_{2}$ as the metal precursor), $\mathrm{N}$-(cyclopentylmethyl)aniline was obtained in good yield $(75 \%)$.

SulP1-MOF-808(Hf)-Rh gave good yields of ortho-substituted alkyl derivatives of anilines with cyclopentene (72-75\%) and excellent yields (81-87\%) were observed for ortho and para substituted halide derivatives of aniline with cyclohexene. The resonance at $+30 \mathrm{ppm}$ in the ${ }^{31} \mathrm{P}$ MAS NMR spectrum of the MOF post-catalysis, shows the metal complex remains intact (Figure S58). ${ }^{[18]}$ For comparison, the ${ }^{31} \mathrm{P}$ chemical shift for the original, unbound phosphine is $-3 \mathrm{ppm}$ and that of the corresponding phosphine oxide is $+40 \mathrm{ppm}$. The tunable nature of SulP1-MOF-808(Hf) to act as a bifunctional ligand with judicious choice of metal sources was therefore, demonstrated in tandem reductive amination and domino hydroaminomethylation reactions.
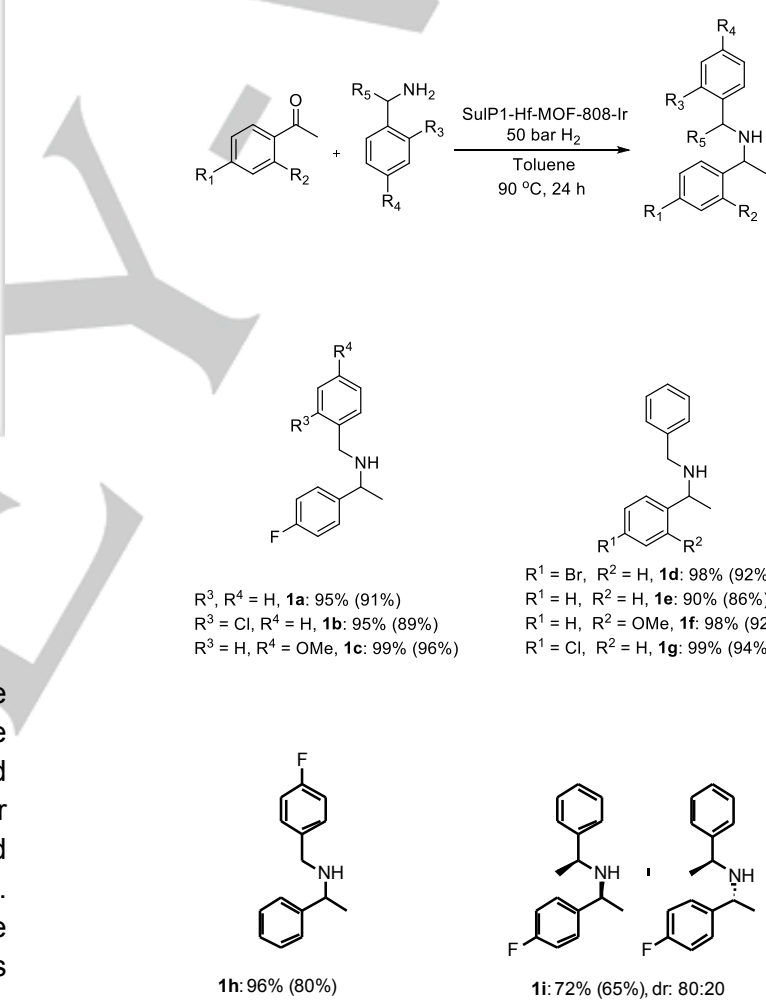

Scheme 2. Reductive amination of a range of functionalised aromatic ketones by SulP1-MOF-808(Hf)-Ir. Reaction conditions: $1 \mathrm{mmol}$ of ketone, $1.3 \mathrm{mmol}$ of benzyl amine, $1.5 \mathrm{~mol} \%$ SulP1-MOF-808(Hf) and $0.37 \mathrm{~mol} \%$ of $\mathrm{Ir}$ as $[\mathrm{Ir}(\mathrm{COD}) \mathrm{Cl}]_{2}$ in $5 \mathrm{~mL}$ toluene under 50 bar of $\mathrm{H}_{2}$ at $90{ }^{\circ} \mathrm{C}$ for $24 \mathrm{~h}$. ${ }^{[b]}$ Conversions are determined by ${ }^{19} \mathrm{~F}$ NMR and ${ }^{1} \mathrm{H}$ NMR in the presence of 1-methylnaphthalene as internal standard. Isolated yields in brackets. 


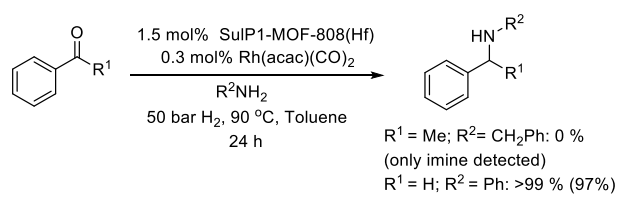

Scheme 3. Reductive amination of aromatic aldehydes and ketones with benzylamine using SuIP1-MOF-808(Hf)-Rh. Standard reaction conditions: $1 \mathrm{mmol}$ of benzaldehyde, $1.3 \mathrm{mmol}$ of benzyl amine, $1.5 \mathrm{~mol} \%$ SulP1-MOF-808(Hf) and $0.3 \mathrm{~mol} \% \mathrm{Rh}(\mathrm{acac})(\mathrm{CO})_{2}$. Conversion determined ${ }^{1} \mathrm{H}$ NMR using 1-methylnaphthalene as internal standard. Isolated yields in brackets.
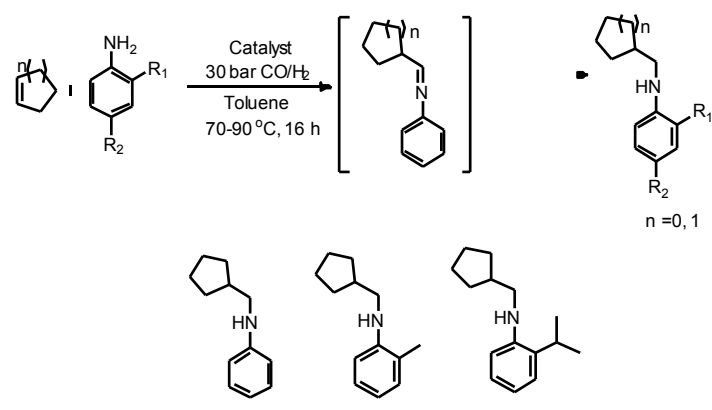

$2 \mathrm{a}(75 \%)$

$$
2 \mathrm{~b}(72 \%)
$$

$2 \mathrm{c}(75 \%)$

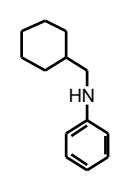

$2 \mathrm{~d}(83 \%)$

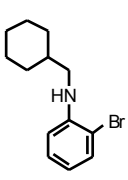

$2 \mathrm{e}(81 \%)$

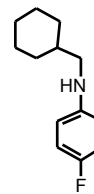

$2 f(87 \%)$
Scheme 4. Hydroaminomethylation of alkenes. Reaction Conditions: 1 $\mathrm{mmol}$ of cyclopentene/cyclohexene, $1.1 \mathrm{mmol}$ of aniline, $1.5 \mathrm{~mol} \%$ SulP1-MOF-808(Hf) and $0.3 \mathrm{~mol} \% \mathrm{Rh}(\mathrm{acac})(\mathrm{CO})_{2}$ in $5 \mathrm{~mL}$ toluene under 30 bar of $\mathrm{CO} / \mathrm{H}_{2}$ at $70{ }^{\circ} \mathrm{C}$ (cyclopentene) $/ 90^{\circ} \mathrm{C}$ (cyclohexene) for $16 \mathrm{~h}$. Isolated yields in brackets.

\section{Conclusion}

We have developed a one-step post-synthetic method to incorporate triarylphosphine moieties into the highly Lewis acidic MOF-808(Hf) without the phosphine undergoing oxidation, using aryl sulfonated phosphines as precursors. The SulP1MOF-808(Hf) thus obtained provides a versatile platform for subsequent functionalisation with desired metals by coordination to generate bifunctional catalysts with inherent Lewis acidic and metal-phosphine complex properties. Upon reaction with $[\mathrm{IrCl}(\mathrm{COD})]_{2}$ the SulP1-MOF-808(Hf) forms SulP1MOF-808(Hf)Ir, which was found to be a highly active pre-catalyst for reductive aminations of functionalised acetophenones with benzyl amine derivatives. Furthermore, SulP1MOF-808(Hf)-Rh obtained via coordination of $\mathrm{Rh}(\mathrm{acac})(\mathrm{CO})_{2}$ with SulP1MOF$808(\mathrm{Hf})$ acts as an excellent catalyst for hydroaminomethylation of alkenes.

\section{Experimental Section}

All chemicals were purchased from chemical suppliers and used without any further purifications. Zirconyl chloride octahydrate $\left(\mathrm{ZrOCl}_{2} .8 \mathrm{H}_{2} \mathrm{O}\right) 98 \%$, hafnium dichloride oxide octahydrate $\left(\mathrm{HfOCl}_{2} .8 \mathrm{H}_{2} \mathrm{O}\right), 98+\%, 1,3,5$-benzene tricarboxylic acid, 98\%, (BTC), 1,3,5-tri(4-carboxyphenyl)benzene, 97\%, formic acid $97 \%$, and $\mathrm{N}, \mathrm{N}$-diethylformamide $99 \%$, were purchased from Alfa Aesar. Benzene-1,4-dicarboxylic acid (BDC) was purchased from SigmaAldrich. N,N- Dimethylformamide (DMF) was purchased from Acros Organics. Tetracarboxyphenyl porphyrin from Frontier Scientific and acetone from Fisher Scientific. Azobenzenedicarboxylic acid (ABDC), ${ }^{[19]} 4,4^{\prime}, 4^{\prime \prime}-(1,3,5$-triazine2,4,6-triyl)tribenzoic acid (TATB), ${ }^{[20,21]}$ and 4,4',4"-(2,4,6-trimethylbenzene$1,3,5$-triyl)tribenzoic acid (TMTB), ${ }^{[22,23]}$ were synthesised in the lab. Room temperature studies refers to temperature range from $15-25^{\circ} \mathrm{C}$. All the MOFs were synthesised using a Carbolite programmable oven equipped with 3216 programmable controllers. Heating the reaction mixture for linker synthesis and/or catalysis is performed by using an oil bath (paraffin oil) on Heidolph MR 3003 magnetic stirring hotplate or IKA® C-MAG HS7 hotplate. Powder X-ray Diffraction (PXRD) patterns on finely ground powder of the MOFs were collected in Debye-Scherrer geometry from Stoe STAD i/p diffractometers with primary monochromation ( $\mathrm{Cu} \mathrm{K}_{\mathrm{a} 1}, \lambda=1.54056 \AA$ ), using 0.5 or $0.7 \mathrm{~mm}$ quartz glass capillaries. Thermogravimetric analysis (TGA) of all MOF samples were carried out on a Netzsch TGA 760 for a temperature range from $20-900{ }^{\circ} \mathrm{C}$ at a heating rate of $5{ }^{\circ} \mathrm{C} \mathrm{min}-1$ in a continuous air flow. ICP analysis was performed on Thermo Fisher Scientific ICP-OES ICAP 6000 series, using hafnium and phosphorus standard for ICP from TraceCERT®, Sigma-Aldrich. $\mathrm{N}_{2}$ adsorption isotherms for all samples were measured volumetrically on a Micrometrics Tristar after heating the sample under vacuum at optimised temperatures (see synthesis of MOFs for exact activation temperatures for each MOF). Solid-state nuclear magnetic resonance (SS-NMR) spectra were recorded using a Bruker Avance III spectrometers equipped with either 9.4 or 14.1 $\mathrm{T}$ superconducting magnets (Larmor frequencies of 161.98 and 242.99 $\mathrm{MHz}$, respectively for ${ }^{31} \mathrm{P}$ ). Samples were packed into standard $\mathrm{ZrO}_{2}$ rotors with outer diameters of $4 \mathrm{~mm}$ and rotated at the magic angle at a rate of 10-14 $\mathrm{kHz}$. Spectra were recorded with signal averaging for between 8 and 128 transients with a recycle interval of between 30 and $120 \mathrm{~s}$. Chemical shifts are reported in ppm relative to $85 \%$ aqueous $\mathrm{H}_{3} \mathrm{PO}_{4}$, using $\mathrm{BPO}_{4}$ as a secondary solid reference $(\delta=-29.6 \mathrm{ppm})$. A first principles periodic Density Functional Theory (DFT) calculation was performed based on the plane wave pseudopotential method as implemented in the program CASTEP. The interaction between core and valence electrons was described by ultrasoft pseudopotentials and the Perdew-Burke-Ernzerhof (PBE) generalised gradient approximation (GGA) was used to describe the exchange-correlation energy for the valence electrons. A cut-off energy of $500 \mathrm{eV}$ was used for the plane wave basis sets. The convergence criteria used for geometry optimisation were $2 \times 10^{-5} \mathrm{eV} /$ atom for the maximum energy change, $0.05 \mathrm{eV} / \AA$ for the maximum change in force and $0.002 \AA$ for the maximum atom displacement. Solution-state NMR analyses were carried out at room temperature on deuterated solvents. Chemical shifts are quoted as parts per million (ppm). Coupling constants, $J$, are quoted in $\mathrm{Hz}$. Multiplicities are indicated by: $\mathrm{s}$ (singlet), $d$ (doublet), $t$ (triplet) and $\mathrm{m}$ (multiplet). ${ }^{1} \mathrm{H},{ }^{13} \mathrm{C},{ }^{31} \mathrm{P},{ }^{19} \mathrm{~F}$ NMR were carried out using either a Bruker Avance $300\left(300 \mathrm{MHz}\right.$ for ${ }^{1} \mathrm{H}, 75 \mathrm{MHz}$ for ${ }^{13} \mathrm{C}$, $121 \mathrm{MHz}$ for ${ }^{31} \mathrm{P}$ and $282 \mathrm{MHz}$ for $\left.{ }^{19} \mathrm{~F}\right)$ or Bruker Ultrashield $500(500 \mathrm{MHz}$ for ${ }^{1} \mathrm{H}, 125 \mathrm{MHz}$ for ${ }^{13} \mathrm{C}, 201 \mathrm{MHz}$ for ${ }^{31} \mathrm{P}$ and $470 \mathrm{MHz}$ for ${ }^{19} \mathrm{~F}$ ). TLC visualization was carried out using a UV lamp (254 nm) or using a $1 \%$ potassium permanganate aqueous solution. Flash silica chromatography was performed using Kieselgel 60 silica.

\section{Synthesis of MOFs}

\section{UiO-66(Zr)}

UiO-66(Zr) was synthesised by following the method reported by Vermoortele et al. ${ }^{[24]}$ without any further modifications. To a $1 \mathrm{~L}$ Schott DURAN pressure plus bottle equipped with a magnetic stirrer bar, $3.5 \mathrm{~g}$ of $\mathrm{ZrCl}_{4}(15 \mathrm{mmol}), 2.5 \mathrm{~g}$ BDC (15 mmol) and $155 \mathrm{~mL}$ of DMF was added and stirred until the solution became homogeneous. To which, $1.5 \mathrm{~mL}$ of $\mathrm{HCl}(17 \mathrm{mmol})$ and $11.5 \mathrm{~mL}$ of $\mathrm{CF}_{3} \mathrm{COOH}$ was added and stirred for $5 \mathrm{~min}$. After the removal of magnetic stirrer bar, the bottle was capped and placed in a preheated oven at $120^{\circ} \mathrm{C}$ for $21 \mathrm{~h}$. After cooling to room temperature, the white powder formed was collected by centrifugation and washed 3 times each with DMF and methanol. The precipitate was dried at $80{ }^{\circ} \mathrm{C}$ overnight and activated at $150{ }^{\circ} \mathrm{C}$ for $\mathrm{N}_{2}$ adsorption. 


\section{Zr-ABDC (Zirconium-Azobenzenedicarboxylic acid)}

$\mathrm{Zr}$-ABDC was synthesised according to the procedure reported by Schaate et al. ${ }^{[19]} 120 \mathrm{mg}$ of $\mathrm{ZrCl}_{4}(0.51 \mathrm{mmol})$ with $1.884 \mathrm{~g}$ of benzoic acid $(15.43 \mathrm{mmol})$ was added to $20 \mathrm{~mL}$ DMF in a screw capped scintillation vial. After sonication for $40 \mathrm{~min}, 139 \mathrm{mg}$ of 4,4-azobenzenedicarboxylic acid was added to the clear solution obtained and further sonicated for $10 \mathrm{~min}$. The resulting solution after addition of $0.05 \mathrm{~mL}$ of water was heated to $120^{\circ} \mathrm{C}$ in a programmable oven at a ramp rate of $5{ }^{\circ} \mathrm{C} / \mathrm{min}$ and kept at the same for $48 \mathrm{~h}$ before being cooled to room temperature. The crystalline product obtained was filtered, washed multiple times with DMF and acetone and kept in acetone for $36 \mathrm{~h}$ with exchanged once in every $12 \mathrm{~h}$. After removal of acetone, the solid was dried overnight at $80{ }^{\circ} \mathrm{C}$. Sample was activated at $150{ }^{\circ} \mathrm{C}$ for $16 \mathrm{~h}$ under vacuum prior to $\mathrm{N}_{2}$ adsorption studies.

\section{3. $\mathrm{PCN}-222(\mathrm{Zr})$}

The published work by Liu et al. ${ }^{[25]}$ was followed for the synthesis of PCN222(Zr). Two different stock solutions were made in $30 \mathrm{~mL}$ scintillation vials:

Stock 1: $200 \mathrm{mg} \mathrm{ZrOCl} \cdot .8 \mathrm{H}_{2} \mathrm{O}(0.620 \mathrm{mmol}), 3.0 \mathrm{~g}$ of benzoic acid $(25 \mathrm{mmol})$ in $20 \mathrm{~mL}$ of DMF.

Stock 2: $100 \mathrm{mg}$ of 5,10,15,20-tetrakis(4-carboxyphenyl)porphyrin (0.126 $\mathrm{mmol}$ ) in $20 \mathrm{~mL}$ DMF.

After sonicating for $30 \mathrm{~min}$, both solutions were heated at $100{ }^{\circ} \mathrm{C}$ in a preheated non-programmable oven for an hour. After that in a $20 \mathrm{~mL}$ glass vial, $4 \mathrm{~mL}$ of solution from each stock together with $0.2 \mathrm{~mL}$ of trifluoroacetic acid were mixed and heated in a preheated oil bath at $120{ }^{\circ} \mathrm{C}$ for an hour. The purple coloured precipitate thus obtained was collected by centrifugation (10 min, $15000 \mathrm{rpm}$ ). The solid was washed multiple times with DMF and immersed in DMF for $48 \mathrm{~h}$ with DMF exchanged once in every $16 \mathrm{~h}$ followed by solvent exchange with acetone and kept in acetone for $48 \mathrm{~h}$ with acetone replaced in every $24 \mathrm{~h}$. After removal of the solvent, the solid was dried at $80{ }^{\circ} \mathrm{C}$ overnight. Sample was activated at $150{ }^{\circ} \mathrm{C}$ for $16 \mathrm{~h}$ under vacuum prior to $\mathrm{N}_{2}$ adsorption studies.

For removal of cluster coordinated benzoic acid groups, following the procedure by Farha et al. ${ }^{[25]} 100 \mathrm{mg}$ of $\mathrm{PCN}-222(\mathrm{Zr})$ was soaked in $15 \mathrm{~mL}$ of DMF and $0.75 \mathrm{~mL}$ of $8 \mathrm{M}$ aq. $\mathrm{HCl}$ was added. The mixture was subsequently heated in a preheated oven at $120{ }^{\circ} \mathrm{C}$ for $12 \mathrm{~h}$. After cooling to room temperature, the white solid was collected by centrifugation (10 $\mathrm{min}, 15000$ rpm), washed multiple times with DMF and acetone and immersed in acetone for $48 \mathrm{~h}$ with acetone replaced in every $24 \mathrm{~h}$. After removal of acetone, the solid was dried at $80{ }^{\circ} \mathrm{C}$ overnight. Sample was activated at $150{ }^{\circ} \mathrm{C}$ for $16 \mathrm{~h}$ under vacuum prior to $\mathrm{N}_{2}$ adsorption studies.

\section{4. $\mathrm{PCN}-224(\mathrm{Zr})$}

$\mathrm{PCN}-224(\mathrm{Zr})$ was synthesised by following the procedure developed by Feng et al. ${ }^{[26]} 60 \mathrm{mg}$ of $\mathrm{ZrCl}_{4}(0.25 \mathrm{mmol}), 20 \mathrm{mg}$ of TCPP $(0.025 \mathrm{mmol})$ and benzoic acid were ultrasonically dissolved in a $4 \mathrm{~mL}$ DMF on a $35 \mathrm{~mL}$ glass vial. The resulting solution was gradually heated to $120^{\circ} \mathrm{C}$ with a ramp rate of $5{ }^{\circ} \mathrm{C} / \mathrm{min}$ and kept there for $24 \mathrm{~h}$ before being cooled to room temperature. After cooling down to room temperature at $5^{\circ} \mathrm{C} / \mathrm{min}$, the supernatant solution was removed via pipette and the reddish-purple solid was kept in fresh DMF for $48 \mathrm{~h}$ with DMF exchanged in every $24 \mathrm{~h}$. The DMF exchanged solid was then immersed in acetone for $48 \mathrm{~h}$ with acetone exchanged in every $24 \mathrm{~h}$ before being filtered and washed with acetone for multiple times and dried overnight at $80^{\circ} \mathrm{C}$

For removal of cluster coordinated benzoic acid groups, following the procedure by Farha et al. ${ }^{[25]} 100 \mathrm{mg}$ of $\mathrm{PCN}-224(\mathrm{Zr})$ was soaked in $15 \mathrm{~mL}$ of DMF and $0.75 \mathrm{~mL}$ of $8 \mathrm{M}$ aq. $\mathrm{HCl}$ was added. The mixture was subsequently heated in a preheated oven at $120{ }^{\circ} \mathrm{C}$ for $12 \mathrm{~h}$. After cooling to room temperature, the white solid was collected by centrifugation (10 $\mathrm{min}, 15000$ $\mathrm{rpm})$, washed multiple times with DMF and acetone and immersed in acetone for $48 \mathrm{~h}$ with acetone replaced in every $24 \mathrm{~h}$. After removal of acetone, the solid was dried at $80{ }^{\circ} \mathrm{C}$ overnight. Sample was activated at $150{ }^{\circ} \mathrm{C}$ for $16 \mathrm{~h}$ under vacuum prior to $\mathrm{N}_{2}$ adsorption studies.

\section{NU-1200(Zr)}

The published work by Liu et al. ${ }^{[27]}$ was slightly modified to obtain NU-1200(Zr) $48 \mathrm{mg}$ of $\mathrm{ZrCl}_{4}(0.20 \mathrm{mmol}), 40 \mathrm{mg}$ of TMTB $(0.08 \mathrm{mmol})$ and $1.40 \mathrm{~g}$ of benzoic acid or $1.61 \mathrm{~g}$ 2-fluorobenzoic acid $(11.5 \mathrm{mmol})$ were ultrasonically dissolved in $8 \mathrm{~mL}$ of DMF in a glass vial (total volume of the vial $\approx 35 \mathrm{~mL}$ ). The resulting solution was then heated to $120^{\circ} \mathrm{C}$ at a ramp rate of $5{ }^{\circ} \mathrm{C} / \mathrm{min}$ in a programmable oven and kept for $48 \mathrm{~h}$ under static conditions before being cooled down to room temperature. The supernatant solution was extracted with a syringe and the crystalline solid was kept in fresh DMF for $48 \mathrm{~h}$ with DMF exchanged in every $12 \mathrm{~h}$. The DMF exchanged solid was then immersed in acetone for $48 \mathrm{~h}$ with acetone exchanged in every $12 \mathrm{~h}$ before being filtered and washed with acetone for multiple times and dried overnight at $80{ }^{\circ} \mathrm{C}$ Sample was activated at $150{ }^{\circ} \mathrm{C}$ for $16 \mathrm{~h}$ under vacuum prior to $\mathrm{N}_{2}$ adsorption . For removal of cluster coordinated benzoic acid groups, following the procedure by Farha et al. $80 \mathrm{mg}$ of $\mathrm{NU}-1200(\mathrm{Zr})$ was soaked in $12 \mathrm{~mL}$ of DMF and $0.5 \mathrm{~mL}$ of $4 \mathrm{M}$ aq. $\mathrm{HCl}$ was added. The mixture was subsequently heated in a preheated oven at $100{ }^{\circ} \mathrm{C}$ for $24 \mathrm{~h}$. After cooling to room temperature, the white solid was collected by centrifugation (10 min, $15000 \mathrm{rpm}$ ), washed multiple times with DMF and acetone and immersed in acetone for $48 \mathrm{~h}$ with acetone replaced every $24 \mathrm{~h}$. After removal of acetone, the solid was dried at $80{ }^{\circ} \mathrm{C}$ overnight. Sample was activated at $150{ }^{\circ} \mathrm{C}$ for $16 \mathrm{~h}$ under vacuum prior to $\mathrm{N}_{2}$ adsorption studies.

\section{6. $\mathrm{PCN}-\mathbf{7 7 7}(\mathrm{Zr})$}

$\mathrm{PCN}-777(\mathrm{Zr})$ was synthesised by modifying the procedure reported by Feng et al. ${ }^{[21]} 60 \mathrm{mg}(0.135 \mathrm{mmol})$ of TATB and $200 \mathrm{mg}(0.620 \mathrm{mmol})$ of $\mathrm{ZrOCl}_{2} .8 \mathrm{H}_{2} \mathrm{O}$ is weighed out to a glass vial. $12 \mathrm{~mL}$ of DEF was measured out separately, to which $0.6 \mathrm{~mL}$ of trifluoroacetic acid was added. The resulting solution was immediately added to the precursors and sonicated at room temperature for $50 \mathrm{~min}$. The clear solution thus obtained is then heated to $120{ }^{\circ} \mathrm{C}$ at a ramp rate of $5{ }^{\circ} \mathrm{C} / \mathrm{min}$ in a programmable oven and kept at the same for $48 \mathrm{~h}$ under static conditions before being cooled down to room temperature. The supernatant solution was removed, and the white precipitate obtained was washed multiple times with DMF before being kept in fresh DMF for $48 \mathrm{~h}$ with DMF replaced in every $12 \mathrm{~h}$. The DMF immersed sample is then kept in acetone for $48 \mathrm{~h}$ with acetone exchanged once in every $12 \mathrm{~h}$, before being filtered and washed multiple times with acetone and dried at $80{ }^{\circ} \mathrm{C}$ overnight. Sample was activated at $160{ }^{\circ} \mathrm{C}$ for $16 \mathrm{~h}$ under vacuum prior to $\mathrm{N}_{2}$ adsorption studies.

\section{PCN-777(Hf)}

We here report the synthesis of $\mathrm{PCN}-777(\mathrm{Hf})$ for the first time as per our knowledge. The procedure used for the synthesis of $\mathrm{PCN}-777(\mathrm{Zr})$ was modified by replacing $\mathrm{ZrOCl}_{2} .8 \mathrm{H}_{2} \mathrm{O}$ with $\mathrm{HfOCl}_{2} .8 \mathrm{H}_{2} \mathrm{O}$ for $\mathrm{PCN}-777(\mathrm{Hf}) .60 \mathrm{mg}$ $(0.135 \mathrm{mmol})$ of TATB and $254 \mathrm{mg}(0.620 \mathrm{mmol})$ of $\mathrm{HfOCl}_{2} .8 \mathrm{H}_{2} \mathrm{O}$ is weighed out to a glass vial. To $12 \mathrm{~mL}$ of DEF measured out separately, $0.6 \mathrm{~mL}$ of trifluoroacetic acid was added. The resulting solution was immediately added to the precursors and sonicated at room temperature for $1 \mathrm{~h}$. The clear solution obtained is then heated to $120^{\circ} \mathrm{C}$ at a ramp rate of $5{ }^{\circ} \mathrm{C} / \mathrm{min}$ in a programmable oven and kept at the same for $48 \mathrm{~h}$ under static conditions before being cooled down to room temperature. The supernatant solution was removed, and the white precipitate obtained was washed multiple times with DMF before being kept in fresh DMF for $48 \mathrm{~h}$ with DMF replaced in every $12 \mathrm{~h}$. The DMF immersed sample is then kept in acetone for $48 \mathrm{~h}$ with acetone exchanged once in every $12 \mathrm{~h}$, before being filtered and washed multiple times with acetone and dried at $80^{\circ} \mathrm{C}$ overnight. Sample was activated at $160{ }^{\circ} \mathrm{C}$ for $16 \mathrm{~h}$ under vacuum prior to $\mathrm{N}_{2}$ adsorption studies.

\section{MOF-808(Zr)}

Procedure was slightly modified in comparison with the reported. ${ }^{[11]} 45 \mathrm{mg}$ $(0.214 \mathrm{mmol})$ of $\mathrm{BTC}$ and $209 \mathrm{mg}(0.649 \mathrm{mmol})$ of $\mathrm{ZrOCl}_{2} .8 \mathrm{H}_{2} \mathrm{O}$ is weighed out to a glass vial equipped with a stirrer bar. $10 \mathrm{~mL}$ each of DMF and formic acid is measured out separately and mixed thoroughly before addition to the precursors. The resulting solution after being stirred at room temperature for at least $1 \mathrm{~h}$, till the solution become homogeneous is heated to $120^{\circ} \mathrm{C}$ at a ramp rate of $3{ }^{\circ} \mathrm{C} /$ minute in a programmable oven and kept at the same for $48 \mathrm{~h}$ under static conditions before being cooled down to $35^{\circ} \mathrm{C}$. The supernatant solution was removed, and the white precipitate obtained was washed with DMF for $20 \mathrm{~h}$ and followed by filtration and an acetone wash for $20 \mathrm{~h}$ before drying at $80{ }^{\circ} \mathrm{C}$ for overnight. Sample was activated at $150{ }^{\circ} \mathrm{C}$ for $16 \mathrm{~h}$ under vacuum prior to $\mathrm{N}_{2}$ adsorption studies.

\section{MOF-808(Hf)}

MOF-808(Hf) can be synthesised under conditions similar to MOF-808( $\mathrm{Zr}$ ) with reasonable crystallinity. Moreover, as mentioned in the main text, different groups have also reported procedures for the synthesis of the same. We have developed our own method for MOF-808(Hf). $45 \mathrm{mg}(0.214 \mathrm{mmol})$ of BTC and $266 \mathrm{mg}(0.649 \mathrm{mmol})$ of $\mathrm{HfOCl}_{2} \cdot 8 \mathrm{H}_{2} \mathrm{O}$ is weighed out to a glass vial equipped with a stirrer bar. $10 \mathrm{~mL}$ each of DMF and formic acid is measured out separately and mixed thoroughly before addition to the precursors. The resulting solution after being stirred at room temperature for at least $1 \mathrm{~h}$, till the solution become homogeneous is heated to $100^{\circ} \mathrm{C}$ at a ramp rate of 
$3{ }^{\circ} \mathrm{C} /$ minute in a programmable oven and kept at the same for $24 \mathrm{~h}$ under static conditions before being cooled down to $35^{\circ} \mathrm{C}$. The supernatant solution was removed, and the white precipitate obtained was washed with DMF for 20 $\mathrm{h}$ and followed by filtration and an acetone wash for $20 \mathrm{~h}$ before drying at $80{ }^{\circ} \mathrm{C}$ for overnight. Sample was activated at $150{ }^{\circ} \mathrm{C}$ for $16 \mathrm{~h}$ under vacuum prior to $\mathrm{N}_{2}$ adsorption studies.

\section{ScBTB}

We here report the scandium version of InPF-110 reported by Daniel et al. ${ }^{[28]}$. Prior to synthesis $\mathrm{Sc}\left(\mathrm{NO}_{3}\right)_{3} \cdot \mathrm{xH}_{2} \mathrm{O}$ was dried in at $80^{\circ} \mathrm{C}$ overnight. $76 \mathrm{mg}(0.33$ $\mathrm{mmol})$ of $\mathrm{Sc}\left(\mathrm{NO}_{3}\right)_{3} \cdot \mathrm{xH}_{2} \mathrm{O}$ and $66 \mathrm{mg}(0.15 \mathrm{mmol}) \mathrm{BTB}$ was added to a Teflonliner. After the addition of $2.5 \mathrm{~mL}$ of DMF, $0.8 \mathrm{~mL}$ nitric acid was added and stirred at room temperature for an hour. The Teflon-liner was then sealed inside a stainless-steel autoclave and placed in a preheated oven at $150{ }^{\circ} \mathrm{C}$ and kept at the same for $4 \mathrm{~h}$. After cooling to room temperature, the needle shaped crystals obtained was collected by filtration, washed multiple times with DMF, followed by ethanol wash and kept in methanol overnight. The solvent was removed on the next day and dried at $80^{\circ} \mathrm{C}$ for $24 \mathrm{~h}$. Sample was activated at $160{ }^{\circ} \mathrm{C}$ under vacuum for $16 \mathrm{~h}$, before nitrogen adsorption studies.

\section{MIL-100(Sc)}

MIL-100(Sc) was synthesised by following the procedure developed in house. ${ }^{[29]} 90 \mathrm{mg}(0.43 \mathrm{mmol}) \mathrm{BTC}$ and $0.6 \mathrm{~mL}(1.45 \mathrm{M})$ aq. $\mathrm{ScCl}_{3}$ solution was added to $20 \mathrm{~mL}$ DMF in a Teflon-liner and stirred vigorously for $45 \mathrm{~min}$. The Teflon-liner was then sealed inside a stainless-steel autoclave and heated to $150{ }^{\circ} \mathrm{C}$ at a ramp rate of $3{ }^{\circ} \mathrm{C} / \mathrm{min}$ and kept at the same for $48 \mathrm{~h}$. After cooling to room temperature, the white precipitate obtained was collected by filtration, washed multiple times with DMF, followed by ethanol wash and kept in methanol overnight. The solvent was removed on the next day and dried at $80^{\circ} \mathrm{C}$ for $24 \mathrm{~h}$. Sample was activated at $160^{\circ} \mathrm{C}$ under vacuum for $16 \mathrm{~h}$, before nitrogen adsorption studies.

Tips: Errors in weighing out accurate amount of precursor materials were found to reduce the crystallinity of the synthesised materials as detected by PXRD

Error limits: $+0.5 \mathrm{mg}$ for metal and $+0.4 \mathrm{mg}$ for linker precursors respectively. For example: Between 45.1 - $45.4 \mathrm{mg}$ (max) of BTC and 266.1-266.5 mg of $\mathrm{HfOCl}_{2} \cdot 8 \mathrm{H}_{2} \mathrm{O}$ were accurately weighed out for the synthesis of MOF-808(Hf) in all cases. Similar error limits were applied for all the MOFs synthesised and tested in catalysis.

\section{Post-synthetic modifications (PSM) on MOF-808/Hf-MOF-808}

\section{Synthesis of MOF-808(Hf)-PTSA}

To $300 \mathrm{mg}$ of MOF-808(Hf) activated at $150{ }^{\circ} \mathrm{C}$ for $16 \mathrm{~h}, 0.5 \mathrm{mmol} p$ toluenesulfonic acid in $50 \mathrm{~mL}$ distilled water was added and kept at room temperature for $24 \mathrm{~h}$ with occasional stirring every 2-3 h. After $24 \mathrm{~h}$, the water was exchanged with acetone and kept for another $24 \mathrm{~h}$ with occasional stirring every $4 \mathrm{~h}$. After removal of acetone, the MOF was activated at $100{ }^{\circ} \mathrm{C}$ and stored at ambient conditions prior to characterization studies.

\section{Synthesis of SulP1-MOF-808(Hf)}

To $300 \mathrm{mg}$ of MOF-808(Hf) activated at $150{ }^{\circ} \mathrm{C}$ for $16 \mathrm{~h}, 0.04 \mathrm{mmol}(14.5 \mathrm{mg})$ sodium salt of 3-(Diphenylphosphine)benzenesulfonic acid in $50 \mathrm{~mL}$ degassed distilled water was added and kept at room temperature for $24 \mathrm{~h}$ with occasional stirring every 2-3 h under inert atmosphere. After $24 \mathrm{~h}$, the water was exchanged ( ${ }^{31} \mathrm{P}-\mathrm{NMR}$ of the solution after PSE showed no characteristic peaks for free phosphine, confirming successful exchange process) with degassed acetone and kept for another $24 \mathrm{~h}$ with occasional stirring every $4 \mathrm{~h}$. After removal of acetone, the MOF was activated at $100{ }^{\circ} \mathrm{C}$ and stored at ambient conditions before further characterization studies.

\section{4) Synthesis of SuIP2-MOF-808(Hf)}

To $300 \mathrm{mg}$ of MOF-808(Hf) activated at $150{ }^{\circ} \mathrm{C}$ for $16 \mathrm{~h}, 0.04 \mathrm{mmol}(21.16 \mathrm{mg})$ dipotassium salt pf bis(p-sulfonatophenyl)phenylphosphine dihydrate in $50 \mathrm{~mL}$ degassed, distilled water was added and kept at room temperature for $24 \mathrm{~h}$ under inert atmosphere with occasional stirring every 2-3 h. After $24 \mathrm{~h}$, the water was exchanged with degassed acetone and kept for another $24 \mathrm{~h}$ with occasional stirring every $4 \mathrm{~h}$. After removal of acetone, the MOF was activated at $100{ }^{\circ} \mathrm{C}$ and stored at ambient conditions before further characterization studies.

\section{Acknowledgements}

We would like to thank the Engineering and Physical Sciences Research Council and CRITICAT Centre for Doctoral Training for financial support [Ph.D studentship to R. R. R. P; Grant code: EP/L016419/1].

\section{Conflict of Interest}

The authors declare no conflict of interest.

Keywords: Metal-organic frameworks - MOF-808(Hf) • PSM • phosphines $\cdot$ reductive amination.

[1] a) H. Furukawa, K. E. Cordova, M. O'Keeffe, O. M. Yaghi, Science. 2013, 341, 1230444; b) H. -C. Zhou, J. R. Long, O. M. Yaghi, Chem. Rev. 2012, 112, 673-674; c) A. J. Howarth, Y. Liu, P. Li, T. C. Wang, J. T. Hupp, O. K. Farha, Nat. Rev. Mater. 2016, 53, 15018.

[2] a) J. Liu, L. Chen, H. Cui, J. Zhang, L. Zhang, C. -Y. Su, Chem. Soc. Rev. 2014, 43, 6311-6061; b) L. Ma, C. Abney, W. Lin, Chem. Soc. Rev. 2009, 38, 1248-1256; c) A. H. Chughtai, N. Ahmad, H. A. Younus, A. Laypkov, F. Verpoort, Chem. Soc. Rev. 2015, 44, 6804-6849; e) S. M. J. Rogge, A. Bavykina, J. Hajek, H. Garcia, A. I. Olivos-Suarez, A. Sepulveda-Escribano, A. Vimont, G. Clet, P. Bazin, F. Kapteijn, M. Daturi, E. V. Ramos-Fernandez, F. X. Llabres I Xamena, V. Van Speybroeck, J. Gascon, Chem. Soc. Rev. 2017, 46, 3134-3184; f) J. Gascon, A. Corma, F. Kapteijn, F. X. Llabres I Xamena, ACS Catal. 2014, 4, 361-378.

[3] a) L. Mitchell, B. Gonzalez-Santiago, J. P. S. Mowat, M. E. Gunn, P. Williamson, N. Acerbi, M. L. Clarke, P. A. Wright, Catal. Sci. Tech. 2013, 3, 606-617; b) D. Reinares-Fisac, L. M. Aguirre-Díaz, M. Iglesias, N. Snejko, E. Gutiérrez-Puebla, M. A. Monge, F. Gándara, J. Am. Chem. Soc. 2016, 138, 9089-9092; c) D. Liu, C. Zhong, J. Phys. Chem. Lett. 2010, 1, 97-101; d) Z. Hu, D. Zhao, CrystEngComm. 2017, 19, 4066.

[4] a) F. Carson, E. Martinez-Castro, R. Marcos, G. González Miera, K. Jansson, X. Zou, B. Martín-Matute, Chem. Commun. 2012, 51, 10864; b) D. T. Genna, L. Y. Pfund, D. C. Samblanet, A. G. Wong-Foy, A. J. Matzger, M. S. Sanford, ACS Catal. 2016, 6, 3569; c) A. Grigoropoulos, G. F. S. Whitehead, N. Perret, A. P. Katsoulidis, F. M. Chadwick, R. P. Davies, A. Haynes, L. Brammer, A. S. Weller, J. Xiao, M. J. Rosseinsky, Chem. Sci. 2016, 7, 2037; d) K. Manna, T. Zhang. M. Carboni, C. W. Abney, W. Lin, J. Am. Chem. Soc. 2014, 136, 13182; e) X. Lian, Y. Fang, E. Joseph, Q. Wang, J. Li, S. Banerjee, C. Lollar, X. Wang, H. -C. Zhou, Chem. Soc. Rev. 2017, 46, 3386-3401; f) A. Fateeva, P. A. Chater, C. P. Ireland, A. A. Tahir, Y. Z. Khimyak, P. V. Wiper, J. R. Darwant, M. J. Rosseinsky, Angew. Chem. Int. Ed. 2012, 51, 74407444; g) H. Fei, S. M. Cohen, J. Am. Chem. Soc. 2015, 137, $2191-$ 2194; h) P. Horcajada, S.Surble, C. Serre, D. -Y. Hong, Y. -K. Seo, J. S. Chang, J. -M. Grenéche, I. Margiolaki, G. Férey, Chem. Commun, 2007, 2820-2822; i)D. J. Xiao, J. Oktawiec, P. J. Milner, J. R. Long, J. Am. Chem. Soc. 2016, 138, 14371-14379; j) A. Grigoropoulos, A. I. Mckay, A. P. Katsoulidis, R. P. Davies, A. Haynes, L. Brammer, J. Xiao, A. S. Weller, M. J. Rosseinsky, Angew. Chem. Int. Ed. 2018, 130, 1-7.

[5] a) S. A. Burgess, A. Kassie, S. A. Baranowski, K. J. Fritzsching, K. S. Rohr, C. M. Brown, C. R. Wade, J. Am. Chem. Soc. 2016, 138, 1780; b) J. Václavik, M. Servalli, C. Lothscütz, J. Szlachekto, M. Ranocchiari, J. A. van Bokhoven, ChemCatChem. 2013, 5, 692; c) T. Sawano, N. C. Thacker, Z. Lin, A. R. Mclssac, W. Lin, J. Am. Chem. Soc. 2015, 137, 12241; d) A. B. Redondo, F. L. Morel, M. Ranocchiari, J. A. van Bokhoven, ACS Catal. 2015, 5, 7099; e) T. Sawano, Z. Lin, D. Boures, B. An, C. Wang, W. Lin, J. Am. Chem. Soc. 2016, 138, 9783; f) J. He, N. W. Waggoner, S. D. Dunning, A. Steiner, V. M. Lynch, S. M. Humphrey, Angew. Chem. Int. Ed. 2016, 55, 12351; f) A. A. Bezrukov, K. W. Törnroos, P. D. C. Dietzel. Cryst. Growth. Des. 2017, 17, 3257-3266; g) A. A. Bezrukov, P. D. C. Dietzel. Inorg. Chem, 2017, 56, 12830-12838. 
[6] a) K. Na. K. M. Choi, O. M. Yaghi, G. A. Somorjai, NANO Lett. 2014, 14 5979-5983; b) K. M. Choi, K. Na, G. A. Somorjai, O. M. Yaghi, J. Am. Chem. Soc. 2015, 137, 7810-7816; c) P. Falcaro, R. Ricco, A. Yazdi, I. Imaz, S. Furukawa, D. Maspoch, R. Ameloot, J. D. Evans, C. J. Doonan, Coord. Chem. Rev. 2016, 307, 237-254.

[7] a) X. Li, Z. Guo, X. Xiao, T. W. Goh, D. Tesfagaber, W. Huang, ACS Catal. 2014, 4, 3490; b) L. Mitchell, P. Williamson, B. Ehrlichová, A. E. Anderson, V. R. Seymour, S. E. Ashbrook, N. Acerbi, L. M. Daniels, R. I. Walton, M. L. Clarke, P. A. Wright, Chem. Eur. J. 2014, 20, 17185; c) L. M. Aguirre-Díaz, F. Gándara, M. Iglesias, N. Snejko, E. GutiérrezPuebia, M. Angeles Monge, J. Am. Chem. Soc. 2015, 20, 17185; d) A. Amanz, M. Pintado-Sierra, A. Corma, M. Iglesias, F. Sánchez, Adv. Synth. Catal. 2012, 354, 1347; e) R. Srirambalaji, S. Hong, R. Natarajan, M. Yoon, R. Hota, Y. Kim, Y. Ho Ko, K. Kim, Chem Commun. 2012, 48, 11650; f) P. V. Dau, S. M. Cohen, Inorg. Chem 2015, 54, 3134

[8] a) X. Xu, M. Nieuwenhuyzen, S. L. James, Angew. Chem. Int. Ed. 2002, 41, 764; b) S. M. Humphrey, P. K. Allan, S. E. Oungoulian, M. S. Ironside, E. R. Wise, Dalton Trans. 2009, 38, 2298; c) S. M. Humphrey, S. E. Oungoulian, J. W. Yoon, Y. K. Hwang, E. R. Wise, J. -S. Chang, Chem. Commun. 2008, 44, 2891; d) A. M. Bohnsack, I. A. Ibarra, V. I. Bakhmutov, V. M. Lynch, S. M. Humphrey, J. Am. Chem. Soc. 2013, 135, 16038; e) A. A. Bezrukov, P. D. C. Dietzel, Inorg. Chem. 2017, 56, 12830-12838; f) A. A. Bezrukov, K. W. Törnroos, P. D. C. Dietzel, Cryst Growth. Des. 2017, 17, 3257-3266; g) A. A. Bezrukov, K. W. Törnroos, E. Le Roux, P. D. C. Dietzel, Chem. Commun. 2018, 54, 2735-2738.

[9] a) H. Furukawa, F. Gándara, Y. -B. Zhang, J. Jiang, W. L. Queen, M. R. Hudson, O. M. Yaghi, J. Am. Chem. Soc. 2014, 136, 4369-4381; b) S. Y Moon, Y. Liu, J. T. Hupp, O. K. Farha, Angew. Chem, Int. Ed. 2015, 54, 6795-6799;

[10] K. Healey, W. Liang, P. D. Southon, T. L. Church, D. M. DÁlessandro, J. Mater. Chem. A. 2016, 4, 10816-10819.

[11] a) J. Jiang, F. Gándara, Y. -B. Zhang, K. Na, O. M. Yaghi, W. G. Klemperer, J. Am. Chem. Soc. 2014, 136, 12844-12847.

[12] a) Y. Liu, R. C. Klet, J. T. Hupp, O. K. Farha, Chem. Commun. 2016, 52 , 7806-7809; b) S. R. -Buzo, P. G. -Gárcia, A. Corma, ChemSusChem. 2017, 10, 1-8; c) L. H. T. Nguyen, T. T. Nguyen, H. L. Nguyen, T. L. H. Doan, P. H. Tran, Catal. Sci. Technol. 2017, 7, 4346-4350. E. Plessers, G. Fu, C. Y. X. Tan, D. E. De Vos, M. B. J. Roeffaers, Catalysis. 2016 6, 104; d) N. E. Thornburg, Y. Liu, P. Li, J. T. Hupp. O. K. Farha, J. M. Notestein, Catal. Sci. Technol. 2016, 6, 6480-6484; e) C. A. -Suárez, S P. -Beltran, G. E. R. -Caballero, P. B. Balbuena, Catal. Sci. Technol. 2018, 8, 847-857.

[13] S. J. Clark, M. D. Segall, C. J. Pickard, P. J. Hasnip, M. J. Probert, K. Refson, M. C. Payne, Zeitschrift für Kristallographie. 2005, 220, $567-$ 570.

[14] a) H. Huang, Y. Zhao, Y. Yang, Le. Zhou, M. Chang Org. Lett. 2017, 19, 1942-1945; b) P. Yang, L. H. Lim, P. Chuanprasit, H, Hirao, J. Zhou, Angew. Chem. Int. Ed. 2016, 55, 12083; c) H. Huang, X. Liu, L. Zhou, M. Chang, X. Zhang, Angew. Chem. Int. Ed. 2016. 55, 5309; d) H. Zhou, Y. Liu, S. Yang, L. Zhou, M. Chang, Angew. Chem. Int. Ed, 2017. 129, 2769-2773; e) C. Li, B. Villa-Marcos, J. Xiao, J. Am. Chem. Soc. 2009, $131,6967$.

[15] a) T. C. Nugent, M. El-Shazly, V. N. Wakchaure, J. Org. Chem. 2008, 73, 1297-1305; b) T. C. Nugent, M. El-Shazly, Adv. Synth. Catal. 2010, 352, 753-819; c) Y. Chi, Y. -G. Zhou, X. Zhang, J. Org. Chem. 2003, 68, 4120-4122; d) Y. Zhang, Q. Yan, G. Zi, G. Hou, Org. Lett. 2017, 19, 4215-4218; e) X. Tan, S. Gao, W. Zeng, S. Xin. Q. Yin, X. Zhang, J. Am. Chem. Soc. 2018, 140, 2024-2027.

[16] A. E. Anderson, C. J. Baddeley, P. A. Wright, Catalysis Lett. 2018, 48, 154-163

[17] a) S. Oda, J. Franke, M. J. Krische, Chem. Sci. 2016, 7, 136-141; b) P. Kalck, M. Urrutigoity, Chem. Rev. 2018, 118, 3833-3861; c) S. Oda, B. Sam, M. J. Krische, Angew. Chem. Int. Ed. 2015, 54, 8525-8528; d) C Chen, S. Jin, Z. Zhang, B. Wei, H. Wang, K. Zhang, H. Lv, X. -Q. Dong, X. Zhang, J. Am. Chem. Soc. 2016, 138, 9017-9020; e) H. Klein, R. Jackstell, M. Kent, A. Martin, M. Beller, Chem. Eng. Technol. 2007, 30, 721-725; f) A. Behr, A. Kämper, R. Kuhimann, A. J. Vorholt, R. Franke,
Catal. Sci. Technol. 2016, 6, 208-214; g) J. Liu, C. Kubis, R. Franke, R. Jackstell, M. Beller, ACS Catal. 2016, 6, 907-912.

[18] D. Dehe, L. Wang, M. K. Müller, G. Dörr, Z. Zhou, R. N. Klupp-Taylor, Y. Sun, S. Ernst, M. Hartmann, M. Bauer, W. R. Thiel, ChemCatChem. 2015, 7, 127-136.

[19] A. Schaate, S. Dühnen, G. Platz, S. Lilienthal, A. M. Schneider, P. Beherens, Eur. J. Inorg. Chem. 2012, 24, 790-796

[20] E. Mühlbauer, A. Kilnkebiel, O. Beyer, F. Auras, S. Wuttke, U. Lüning, T. Bein, Microprous Mesoporous Mater. 2015, 216, 51-55.

[21] D. Feng, K. Wang, J. Su, T. -F. Liu, J. Park, Z. Wei, M. Bosch, A. Yakovenko, X. Zou, H. -C. Zhou, Angew. Chem. Int. Ed. 2014, 54, 149154.

[22] A. M. Bumstead, D. B. Cordes, D. M. Dawson, K. K. Chakarova, M. Y. Mihaylov, C. L. Hobday, T. Düren, K. I. Hadjivanov, A. M. Z. Slawin, S. E. Ashbrook, R. R. R. Prasad, P. A. Wright, Chem. Eur. J. 2018, 24, 6115-6126.

[23] B. Wang, X. -L. Lv, D. Feng, L. -H. Xie, J. Zhang, M. Li, Y. Xie, J. -R. Li, H. -C. Zhou, J. Am. Chem. Soc. 2016, 138, 6204-6216.

[24] F. Vermoortele, B. Bueken, G. Le Bars, B, Van de Voorde, M. Vandichel, K. Houthoofd, A. Vimont, M. Daturi, M. Warquier, V. V. Speybroeck, C. Krischhock, D. E. De Vos, J. Am. Chem. Soc. 2013, 135,11465-1168.

[25] Y. Liu, S. Y. Moon, J. T. Hupp, O. K. Farha, ACS Nano. 2015, 9, 1235812364.

[26] D. Feng, W. -C. Chung, Z. Wei, Z. -Yuan Gu, H. -L. Jang, Y. -P. Chen, D. J. Darensbourg, H. -C. Zhou, J. Am. Chem. Soc. 2013, 135, 1710517110.

[27] T. -F. Liu, N. A. Vermeulen, A. J. Howrath, P. Li, A. A. Serjeant, J. T. Hupp, O. K. Farha, Eur. J. Inorg. Chem. 2016, 27, 4349-4352.

[28] D. R. -Fisac, L. M. A. -Diáz, M. Iglesias, N. Snejko, E. G. -Puebla, M. A Monge, F. Gándara, J. Am. Chem. Soc. 2016, 138, 9089-9092.

[29] L. Mitchell, B. G. -Santiago, J. P. S. Mowat, M. E. Gunn, P. Williamson, N. Acerbi, M. L. Clarke, P. A. Wright, Catal. Sci. Technol. 2013, 3, 606617

[30] The research data under[pinning this publication can be accessed at: https://doi.org/10.17630/1d50d4fd-7d29-4f2a-89ff-f9091f6bd4ea 


\section{Entry for the Table of Contents}

Post-synthetic modification of hafnium MOF-808 with sulfonated arylphosphines and precious metal catalyst pre-cursors generates highly active and tunable bifunctional catalysts for reductive amination reactions.

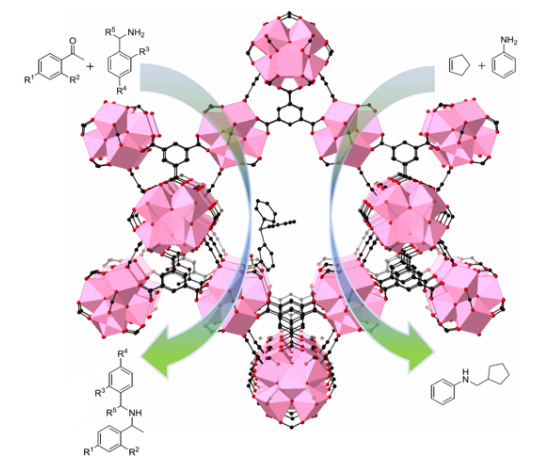

Ram R. R. Prasad, Daniel M. Dawson, Paul A. Cox, Sharon E. Ashbrook, Paul A. Wright* and Matthew L. Clarke*

A Bifunctional MOF Catalyst containing Metal-phosphine and Lewis Acidic Active Sites 